\title{
Developmental Perspectives on Interpersonal Affective Touch
}

\author{
Laura Crucianelli ${ }^{1,3} \cdot$ Maria Laura Filippetti ${ }^{2}$
}

Published online: 12 May 2018

(c) The Author(s) 2018

\begin{abstract}
In the last decade, philosophy, neuroscience and psychology alike have paid increasing attention to the study of interpersonal affective touch, which refers to the emotional and motivational facets of tactile sensation. Some aspects of affective touch have been linked to a neurophysiologically specialised system, namely the C tactile (CT) system. While the role of this system for affiliation, social bonding and communication of emotions have been widely investigated, only recently researchers have started to focus on the potential role of interpersonal affective touch in acquiring awareness of the body as our own, i.e. as belonging to our psychological 'self'. We review and discuss recent developmental and adult findings, pointing to the central role of interpersonal affective touch in body awareness and social cognition in health and disorders. We propose that interpersonal affective touch, as an interoceptive modality invested of a social nature, can uniquely contribute to the ongoing debate in philosophy about the primacy of the relational nature of the minimal self.
\end{abstract}

Keywords Interpersonal affective touch $\cdot$ CT system · Self-other distinction · Development · Psychological self · Body representation

\section{Introduction}

Our first sensorial experiences, which provide us with information about our own body and the surrounding environment arise in the womb. In these early sensory interactions, touch is possibly the first route by which the developing body receives inputs from the external world and gradually shapes one's body boundaries and its capabilities for action (e.g. Atkinson and Braddick 1982; Bernhardt 1987; Bremner et al. 2012). The skin is the largest of our sensory organs and wraps our entire body surface (Serino and Haggard 2010; Gallace and Spence 2014); hence, evidence suggests that touch might play a pivotal role in developing a sense of self as separate from the other (see Field 2010 for a review). Somewhat paradoxically, touch is also our most social sense

Laura Crucianelli

1.crucianelli@ucl.ac.uk

1 Division of Psychology and Language Sciences, University College London, London, UK

2 Centre for Brain Science, Department of Psychology, University of Essex, Colchester, UK

3 Department of Clinical, Educational and Health Psychology, University College London, 1-19 Torrington Place, London WC1E 7HB, UK since it is fundamentally involved in how we explore the environment and engage in successful interactions (Gallace 2012; Ebisch et al. 2014; Gallace and Spence 2014), as well as how we bond with other people and form interpersonal attachments.

In the last decade, philosophy, neuroscience and psychology alike have paid increasing attention to the study of emotional and motivational aspects of touch, which has been referred to as affective touch (see McGlone et al. 2014, for a review). Such slow, gentle touch has generated renowned interest in the scientific community, being the topic of neurophysiological and behavioural investigations. This research supports the existence of a specialised tactile system for interpersonal affective touch (i.e. the CT system; see Sect. 2) that has been shown to play a pivotal role in social development (Fairhurst et al. 2014; Tuulari et al. 2017) and might promote normal cognitive functioning at the early stages of development (see Walker and McGlone 2013 for a review). The communicative power of a caress and the wellbeing derived by a hug are examples of the sociality of touch, and research has widely discussed the effects of affective tactile contact with others in shaping the dynamics of affiliative behaviour (Morrison et al. 2010; Gallace and Spence 2014; von Mohr et al. 2017), such as influencing people's social behaviours (e.g. the "Midas touch effect", Crusco and 
Wetzel 1984; Levav and Argo 2010), and communicating and regulating emotions (Hertenstein et al. 2006).

While the characteristics and role of the interpersonal affective touch system for affiliative behaviours, such as social bonding and communication of emotions has been widely described and discussed in recent research (see Olausson et al. 2002; Löken et al. 2009; Morrison et al. 2010; Walker and McGlone 2013, for reviews), less is known about the potential role of this type of touch on the development of our sense of self. Bodily self-awareness, that is the ability to sense and recognise our body as our own, results from the dynamic interplay between signals arising from both (a) outside the body recruiting sensory modalities such as vision and audition (Blanke and Metzinger 2009); and (b) inside the body, by giving information about the movement and location of the body in the space (e.g. proprioceptive, vestibular and kinaesthetic input) and the perception of its physiological condition (Craig 2010; Critchley et al. 2004). While traditionally philosophy has focused on external senses, recent accounts have re-conceptualised affective touch as a modality providing information about the internal states of the body. This channel is referred to as interoception (Craig 2002, 2008), which can be defined as a variety of visceral signals providing information about the subjective feelings and needs of the body. Interoception contributes to the human capability to maintain optimal physiological balance and has an important role in establishing awareness of ourselves as feeling entities (the so called 'sentient self') at any given time (Craig 2003; Craig 2009).

In the wake of these recent conceptualisations, here we review experimental and clinical evidence supporting the importance of interpersonal affective touch to the way we recognise and make sense of our body as our own. In particular, we focus on the interoceptive facet of affective touch (i.e. subjective bodily pleasure) and its importance-both independently and in relation to exteroceptive informationto the development of body representation. We conclude by proposing that affective touch constitutes a fundamental aspect of bodily self-consciousness (Blanke 2012; Dijkerman 2015) from the very first stages of human life.

\section{Discriminative and Affective Touch}

Perceptual awareness is tacitly considered the fundamental point of contact of an experiencing subject with the external environment and as such it provides the primary basis on which beliefs, concepts and higher-order knowledge may be formed later in life. If this is so, then one basic yet overlooked aspect is that it is touch which provides us with the most basic way to "meet" the world (Ciaunica and Fotopoulou 2017). Growing behavioural and neurobiological evidence supports the centrality of interpersonal touch for social-emotional understanding. Considering its privileged role, several accounts have put forward a neurophysiological distinction of the touch system. Firstly, a discriminative/ exteroceptive modality activates the classical primary and secondary somatosensory cortices and it is mainly involved in rapidly identifying the physical characteristics of a stimulus on the skin (e.g. weight and texture) in order to respond promptly (Penfield and Boldrey 1937; Trulsson et al. 2001; McGlone et al. 2002). Secondly, a slower affective/interoceptive modality is thought to be responsible for the affective states which can be derived from tactile stimulation (Björnsdotter et al. 2009; Craig 2002; Olausson et al. 2002). This paper will specifically focus on the latter one.

Over the last few decades, research has supported the hypothesis that $\mathrm{CT}$ afferents, that is nerve fibers transmitting sensory information to the central nervous system, constitute a distinct anatomical and functional system, which may be specifically activated in response to slow, caress-like types of touch, providing distinctive pleasant sensations (Vallbo et al. 1999; Olausson et al. 2002; Löken et al. 2009). Studies conducted applying a neurophysiological method called microneurography (which allows recording of the activity of single peripheral nerves on the skin) have in fact shown activation of a group of nerve fibers, the $\mathrm{C}$ tactile (CT) afferents, when touch is applied at slow velocities and on the hairy skin of the body (Löken et al. 2009; Vallbo et al. 1999). Activation of these CT-fibers correlates linearly with the subjective report of pleasantness when stroked at velocities between 1 and $10 \mathrm{~cm} / \mathrm{s}$ (Löken and Olausson 2010).

In addition, recent findings showed that CT afferents respond more vigorously to touch stimuli delivered at skin temperature compared to colder or warmer stimuli. This enhanced activation corresponds to higher pleasantness ratings reported in response to touch stimuli that are closer to skin temperature (Ackerley et al. 2014). The $\mathrm{A} \beta$ and $\mathrm{C}$ tactile systems act in parallel when responding to cutaneous stimulation, however the latter one may specifically "pick out" a range of velocities likely to have social-affective relevance in order to provide further emotional processing (Morrison et al. 2010).

The CT fibers are assumed to follow a specific pathway projecting directly to the posterior insular cortex. Functional imaging studies in humans indeed point to this cortical region as a primary target for CT fibers (Olausson et al. 2002; Björnsdotter et al. 2010; but see; Gazzola et al. 2012). Further evidence comes from the study of two unique patients suffering from a neuropathy syndrome, which left intact only the CT afferents of the body (Sterman et al. 1980). Functional magnetic resonance imaging (fMRI) of soft brush stroking on the hairy skin of these patients showed activation in the posterior insular cortex; in contrast, no activation in somatosensory cortices was recorded (Olausson et al. 2002). Therefore, the posterior insula may 
support an early convergence of sensory and affective signals, whereby interoceptive information about the internal state of the body is progressively integrated with information from the exteroceptive senses (e.g. vision, audition, olfaction; Craig 2010; Craig 2009). There is evidence supporting the idea that the exteroceptive and interoceptive modalities interact and can influence each other; this integration of interoceptive/affective and exteroceptive/sensory information seems to be responsible for the awareness of our whole body at any given time, and the construction of the subjective experience of the self (Critchley et al. 2004; Craig 2008). Such integration is crucial for the homeostasis of the body, but it may also contribute critically to the formation of coherent bodily representation, the sensory environment, and motivational conditions.

Neuropsychological findings have provided support for the pivotal role of interoception in the sense of body ownership. Karnath and colleagues for example described patients who, following lesions involving the right insular cortex (a key area for the processing of interoceptive signals), showed disorders of body ownership and self-awareness (Karnath et al. 2005; Karnath and Baier 2010). Recent behavioural studies on healthy individuals seem to further support this account, suggesting that the effect of slow, caress-like touch may have important clinical implications on body representation, and specifically on the way we become aware of our body as our own (Crucianelli et al. 2013, 2017; Lloyd et al. 2013; van Stralen et al. 2014). For example, van Stralen et al. (2011) showed that affective touch might be key in the recovery process of body disownership (somatoparaphrenia). The authors reported the case of a patient who, following an ischemic stroke, showed remarkable improvements in recovering a sense of body ownership by caressing her arm (van Stralen et al. 2011). Therefore, altogether these findings suggest that despite touch being applied to the external surface of the body, it seems to jointly impact both our exteroceptive and interoceptive bodily-self.

In line with Craig (2002), here we support the re-definition of affective touch as an interoceptive modality, which provides information about the internal states of the body with the final aim of homeostatic regulation. This conceptualisation of affective touch has important implications for some potential functions of the mediating CT afferents system, including its developmental trajectories in health and disorders.

\section{Into the Womb: An Early Developmental Perspective on Interpersonal Affective Touch}

As mentioned earlier, touch plays a vital role in early social development. Not only is touch the first modality through which we communicate and interact with the surrounding environment, but most importantly, it is the initial modality through which others initially communicate with us, in early life. Touch is the earliest sensory modality to develop and to become functional prior to any other sensory modalities (e.g. Atkinson and Braddick 1982; Bernhardt 1987). It has been thus hypothesised that interpersonal affective touch might represent the scaffolding through which the social brain develops, as the very first modality which enables us to distinguish our body from others and the environment (see McGlone et al. 2014 for a review).

To track the powerful effects of touch on human development, we need to start from the moment when we are body within a body, skin within a skin. In the womb, the fetus experiences continuous tactile stimulations by being rocked in amniotic fluid and perceiving touch through the mother's abdominal wall, to which the fetus typically respond by showing an increased activity (Field 2010 for review). Less than 6 weeks into the gestation, the embryo shows withdraw movements in response to light stroking of lips and nose (Montague 1978). When the embryo is 9 weeks old, touch in the palms will cause the fingers to bend in a griplike movement; fingers and thumb will close at twelve fetal weeks (Montague 1978). In vitro studies have shown that the human fetus responds to stroking from approximately 8.5 weeks (Hooker 1943, 1952), and that contacts between twins in utero start by the same gestational age, with gentle inter-human contact preceding faster interactions (Arabin et al. 1996). Interestingly, Castiello et al. (2010) recorded the presence of intentional movement between twins in utero from 14 gestational weeks, with slow types of movement specifically directed to the self and twin (compared to movements directed towards the uterine wall). As these tactile responses have been recorded at a developmental stage before specialized low-threshold mechanoreceptors have developed (Humphrey 1966), it has been hypothesised that C fibers may support early bodily and social development (McGlone et al. 2014). The fetus is covered in fine hair (i.e. lanugo hairs) and it has been suggested that fetal movement in the amiotic fluid might directly stimulate CTs afferent, which are known to activate the hypothalamus and insular cortex, promoting an antistress effect via the release of oxytocin, and stimulating the fetal growth (Bystrova 2009).

Neuroimaging studies provide supporting evidence on the recruitment of $\mathrm{CT}$ afferents from prenatal development. 
Bartocci et al. (2006) focused on C-nociceptors in hairy skin (where CT afferents are abundant) and found bilateral activation of the somatosensory cortex in response to painful stimuli (which are partially mediated by the CT system) in preterm neonates (28-36 weeks of gestation) using near-infrared spectroscopy (NIRS). More recent studies indirectly suggested the involvement of CT afferents from the earliest developmental stages, by providing evidence of postnatal development of discriminative touch. Shibata et al. (2012) and Williams et al. (2015) respectively used NIRS and fMRI to demonstrate somatosensory cortex activation in response to discriminative touch in neonates. Additionally, two EEG/ERP studies (Rigato et al. 2014; Saby et al. 2015) have shown somatosensory evoked potential responses elicited by brief tactile stimulation after the first 6 months of life. Based on these findings, the perception of touch in the womb might be mainly (if not entirely) mediated by CT afferents (Bystrova 2009).

While these studies might point towards the presence of an early neural and behavioural processing of touch, only recently research has started to directly investigate the specificity of interpersonal affective touch and its role in shaping social and cognitive development later on. Marx and Nagy (2015) measured fetal behavioural responses to maternal touch to the abdomen compared to maternal voice. Results showed that the fetus responded more vigorously to the external tactile stimulation compared to maternal voice, as measured by means of an increase in arm, head and mouth movements, and a decrease of arm crossing movements (Marx and Nagy 2015). Gentle tactile stimulation on the fetus has been also shown to have longer term consequences. Wang and colleagues found that 3-month-old infants who had received regular slow tactile stimulation before birth showed significantly reduced negative mood while having a higher adaptability, approach, and persistence compared to age-matched infants who received less or no tactile stimulation (Wang et al. 2015). The presence of these temperamental traits point towards long-term positive socio-emotional and cognitive developmental outcome (De Schipper et al. 2004; Veenstra et al. 2006; Gong et al. 2013), suggesting that interpersonal affective touch might be key for establishing and developing self-regulation within the dyadic caregiver-infant interaction. Indeed, regular tactile stimulation could act by reducing mothers' negative emotions and anxiety, with the effect of lowering the level of cortisol in blood and amniotic fluid - thus calming the fetus directly (Baibazarova et al. 2013). Therefore, through affective tactile stimulation, the caregiver might indirectly influence the physiological balance of the fetus, providing arguably the first interoceptive feedback that the infant could learn to selectively recognise and respond to once born. We turn to the discussion of this point now.

\section{A Touch of Love: The Role of Interpersonal Affective Touch in Typical Development}

The separation from the maternal body at birth can be considered as the first traumatic experience we have to face (the so-called "stress of being born"; Lagercrantz and Slotkin 1986). Self-regulation through touch becomes perhaps even more important after birth. Caregiver touch is essential for growth and development; it actively reduces infant stress by increasing positive affect (Stack and Muir 1992) by calming infants in pain and discomfort (Bellieni et al. 2007). Maternal care and skin-to-skin contact allow to maintain, although in a different environment, proximity and connection with the maternal body (i.e. "kangaroo care"; Ferber et al. 2008). As newborns, humans continue to receive constant and sustained tactile stimulations whilst being cuddled and breastfed. Skin-to-skin contact at birth is a standard practice in many country, and it has been shown to promote successful breastfeeding and to improve developmental outcomes following preterm birth (e.g. Moore et al. 2016; Feldman et al. 2014). As evidence of the pivotal role of interpersonal affective touch for early development, a recent ERP study with preterm neonates recorded the presence of stronger brain responses to light air puff on the palm of the hand after skin-to-skin human contact, such as breastfeeding and massage, compared to painful early experiences such as injections and tube insertions (Maitre et al. 2017). This evidence not only suggests the importance of interpersonal tactile exchanges in regular day-to-day interactions, but it also supports the potential role of affective touch in the clinical setting.

Increasing clinical and experimental evidence points to the significance of maternal tactile interactions for the promotion of infants' mental and physical health (e.g. PeláezNogueras et al. 1997; Field 2002; Sharp et al. 2012; Maitre et al. 2017). Through its communicative role, interpersonal tactile interactions have the power of conveying specific perceptions and feelings by varying for example its intensity, velocity or duration (Hertenstein 2002; Kirsch et al. 2017). The communicative value of touch becomes crucial in the first stages of development, when dyadic interactions are essentially preverbal and the caregiver has to sense their infant's needs. In the context of attachment theory (Bowlby 1969), studies support the facilitating role of touch in establishing the social bond between infant and caregivers (Ainsworth 1979; Weiss et al. 2000; Beebe et al. 2010). Intuitively, the presence versus absence of touch can communicate the presence versus absence of the primary caregiver. Nevertheless, this line of research together with other studies on parent-infant interactions (e.g. Stack and Muir 1992; Stack et al. 1996; Feldman et al. 2002; Jean et al. 2014; Reece et al. 2016) suggest 
that it is not merely the availability of maternal touch that affects infant behaviour, but importantly the quality of the touch itself. In general, a vast amount of research has demonstrated that light massage has beneficial effect on a number of different outcome measures, known to relate to the infant's well-being (see Underdown et al. 2006, for a review). More specifically, Stack et al. (1996) found that mothers employ different types of touch in order to elicit a specific behavioural response in the infant (e.g. high levels of tickling and lifting, and low levels of holding in order to elicit infants' smiling). These findings suggest that infants may become sensitive to precise characteristics of their mother's touch (Stack and Muir 1992).

Increasing evidence supports the idea that mothers might use touch in order to emotionally regulate their infant (e.g. Hertenstein and Compos 2001). Maternal soothing techniques in the first months of life strongly rely on tactile strategies, such as holding and rocking (Kopp 1989), which has been shown to effectively reduce infant distress and regulate affect in 2-month-old infants (Jahromi et al. 2004). Additional evidence of the role of maternal touch on emotion regulation comes from a study by Hertenstein and Compos (2001), which showed that specific qualities of tactile stimulation provided by the mother (in the sense of negative/tense and positive/relaxed fingers grip) in a given context can elicit an appropriate emotion or affect in 12-month-old infants.

Altogether these behavioural studies indicate that it is the caregivers' ability to promptly and contingently respond to their infants using affective displays ("maternal sensitivity", Ainsworth and Bell 1972-e.g. mirroring joy in response to a display of enthusiasm in the infant, Gergely and Watson 1999) that can crucially shape infants' development of emotion recognition and self-regulation. According to some developmental theories (e.g. Gergely et al. 2002; Meins et al. 2001), the parental ability to recognise and contingently mirror their infant's mental needs creates a situation of parent-infant synchrony (Feldman et al. 1999), which in turn enables the infant to modulate her or his own affective states. Recently, Fotopoulou and Tsakiris 2017 put forward a proposal on 'embodied mentalization', whereby higher-order social cognitive abilities such as parental mentalization, are translated into specific 'physical' affect exchanges in parentinfant dyads. According to this account, embodied and primarily tactile interactions between infant and caregiver have a key role in shaping the 'minimal' development of body representation (Fotopoulou and Tsakiris 2017). Evidence in support to this proposal come from a recent study, where we show that the maternal inability to understand and interpret the infant's needs and desires translates directly in nonattuned tactile interactions between mother and infant (Crucianelli et al. 2018). Although the theory and the concept of 'embodied mentalization' escapes the scope of this review article, we want to similarly emphasize the unique role of interpersonal affective touch in affect regulation behaviours during parent-infant interactions, and its importance for the development of body representation.

How does touch, rather than other modalities like vision or taste, uniquely affect our sensitivity and appraisal of internal and external bodily signals, and thereby our social interactions? There are at least three aspects that mark out affective touch in comparison with other sensory modalities. What is special about interpersonal affective touch, in comparison to other sensory modalities such as gaze, is that it is inherently mutual, multisensory, and can inform the organism regarding the homeostatic state of the body. (1) Mutual, because interpersonal touch (and the necessary physical contact it entails) is a modality that, in its embodied sense, is intrinsically shared and synchronous (Ciaunica and Fotopoulou 2017). Indeed, we can look without been looked back but we cannot touch someone without being touched in return (Merleau-Ponty 1964). (2) Multisensory, because by requiring physical proximity, touch is accompanied by a cascade of sensory feedback from other bodies, such as smell and vision. (3) Lastly, and of crucial importance here, interpersonal affective touch between an infant and a caregiver represents the basis of how infants progressively learn to regulate their own interoceptive states (the perception of the physiological state of the body) in relation to their exteroceptive states (the perception of the surrounding environment, derived from sensory cues) (Fotopoulou and Tsakiris 2017; see also; Atzil and Barrett 2017; Fonagy and Campbell 2017; Bolis and Schilbach 2017). In support to this, a recent fMRI study by Tuulari et al. (2017) has shown that gentle stroking in neonates activates socio-affective areas of the brain known to be involved in interoceptive processing, such as the insular cortex. Additionally, there are studies suggesting that gentle touch by the caregiver has a direct effect on infants' physiological arousal (Beebe and Lachmann 1998; Rothbart et al. 1992). For example, identifying touch that is more calming is important to foster emotion regulation in infancy, which has important developmental implications (Lowe et al. 2016). Fairhurst et al. (2014) investigated the perception of affective pleasant touch in 9-month-old infants by examining physiological arousal and behavioural engagement in response to touch delivered at different velocities. This study showed that sensitivity to slow, CT-optimal touch led to heart rate deceleration and increased engagement, supporting the idea that this type of touch might play a pivotal role in the regulation of physiological arousal and in influencing early social interactions.

Taken together, this evidence supports the idea that human beings are able to distinguish different facets of tactile interactions from a very early stage of life. As mentioned earlier, interpersonal affective touch functions as both an interoceptive and exteroceptive channel and thus it can provide information both about the external world and 
our internal states, shaping the perception of the other as well as the self. For example, a fabric touching my skin can elicit an internal pleasant feeling and simultaneously convey information about the 'toucher' and their role in this specific interaction, as well as about myself (my boundaries and my subjective feeling at this given time). We propose that, frequent tactile experiences soon after birth allow us to refine our sophisticated sensitivity to interpersonal touch, which might play a pivotal role in the development of self-other distinction, with potentially significant consequences on the way we establish and maintain successful social interactions.

So far, we have stressed the importance of early life experiences on the way, even before being born, infants can learn to respond to changes in the physiological condition of their body via 'embodied proximal interactions' with the caregiver (Fotopoulou and Tsakiris 2017). Importantly, sustained, continuous lack of touch stimulation or impaired sensitivity to affective touch might lead to the atypical subjective experience of interpersonal touch, with potential repercussion on the infant's interoceptive and exteroceptive bodily states, and thereby to their cognitive, emotional and social development. Given that touch is the fundamental point of contact between the self and the external world, any experience of interpersonal affective touch is strongly context dependent. For example, certain tactile interactions can also be perceived as inappropriate on the basis of situational variables. The next session will focus on the link between reduced sensory responsiveness to affective touch, and social and self-awareness.

\section{Atypical Experience of Touch}

\subsection{Impoverished or Unbalanced Interpersonal Affective Tactile Experiences}

Developmental research has shown how early atypical exposure to interpersonal touch can negatively influence infant development (Field 2010 for a review). Among this work, postnatal depression has been extensively shown to impact the quality of mother-infant interaction (Herrera et al. 2004), by influencing the extent to which and how mothers engage in tactile behaviours with their infants. For example, Malphurs et al. (1996) investigated the relation between maternal depression and their tactile interaction with their 6 months-old infants. Mothers with depressive symptoms in this study used touch more often compared to the control group, however the type of touch used was classified as negative, with more instances of rough tickling, poking, and pulling compared to mothers without depressive symptoms. Additionally, other studies have shown that mothers with postnatal depression, in comparison with non-depressed mothers, tend to lift their infants more in order to restrain and control their behaviours and attract their attention, suggesting the presence of intrusive interactions (Field et al. 1996; Herrera et al. 2004).

Research has also focused on the infant behavioural consequences in response to maternal depression. For example, Moszkowski et al. (2009) have found that 6and 10-month-old infants of depressed mothers engage in self-touching behaviours, such as thumb-sucking, to a greater extent compared to infants of non-depressed mothers. These infants also seem to use more active types of touching (i.e. grabbing) in response to stressful situations, as a soothing strategy (Moszkowski et al. 2009). Infants' response to mothers' depressive mood can be considered an important predictor of children's future development (Tronick and Gianino 1986; Murray and Cooper 1997). In fact, the use of comforting behaviour in these infants might represent a self-regulatory strategy to compensate for the lack of positive touch from their primary caregiver, highlighting the primordial need of these tactile interactions from the earliest stages of life. What these studies suggest is that postnatal depression seems to have a strong impact on touch behaviour, as well as on the maternal affective response to the infants' developmental needs and regulatory signals (Tronick and Gianino 1986; Herrera et al. 2004). Most importantly, these findings support the idea that despite touch behaviour in these mothers follows within the 'standard' level, it is its qualitative value that seem to be crucial in predicting infants' self-regulation and socio-affective development.

The dramatic lack of interpersonal affective touch experienced in some extreme situations, such as institutional care, represent another example of the consequences that an impairment in early interpersonal interactions can have on the development of both physical and mental health. Institutional care has been associated with delays in cognitive and neuro-development (Chugani et al. 2001; MacLean 2003; Nelson et al. 2007; Field 2010). Most importantly, these developmental delays and the subsequent cognitive and behavioural deficits seem to persist for many years after adoption (Beckett et al. 2006), highlighting the long-term behavioural, emotional, and cognitive consequences associated with impairments in critical periods of early interpersonal tactile interactions. Considering the role of the CT-system in establishing interoceptive and exteroceptive body representation, it is plausible that these infants and children might experience long-term difficulties in the way they perceive sensory information deriving from the world and the way they detect and appraise changes in the physiological state of their body. It could be argued that a lack of interpersonal affective touch in critical periods of development could lead to hyper- or hypo-sensitivity to these signals, thereby influencing subsequent emotional and social behaviour. 


\subsection{Impaired Perception of Affective Interpersonal Touch}

The second type of atypical experiences of interpersonal touch we mentioned at the beginning of this section are the ones associated with distorted sensory responsiveness to the gentle, slow touch that usually activates the CT system. Focusing on specific clinical populations which have been shown to have a reduced perception of interpersonal affective touch (i.e. reduced subjective pleasantness compared to age-matched healthy controls) offers the unique opportunity to better understand the functions of this specialised tactile system, as well as the causal links and consequences associated with its failure.

While individual differences in the way we respond to social touch on our daily interactions are common (Voos et al. 2012), neuroimaging and behavioural research studies have recently reported impaired perception of interpersonal touch in individuals with Autism Spectrum Disorder (ASD). ASD is a developmental disorder, characterised by impairments in social interaction and communication, and repetitive and restricted behaviours (American Psychiatric Association 2013). Individuals that score high on autistic traits have a lower preference for social touch (Voos et al. 2012) and they show reduced activation to CT-optimal touch in brain areas known to specifically respond to this type of touch (i.e. superior temporal sulcus, STS, and orbitofrontal cortex, OFC) (Voos et al. 2012; Bennett et al. 2013), as well as somatosensory areas (Cascio et al. 2012, 2015).

Interestingly, Cascio et al. (2012) also noted that individuals with ASD showed a hyper-responsiveness to unpleasant tactile stimuli in these same areas, suggesting the presence of a pattern of imbalanced sensory responsiveness compared to the healthy control group. This altered subjective response to tactile stimuli is inherently embedded to the development of embodied interactions, and thereby to the ability to regulate changes in visceral states.

The cortical brain regions that respond to CT-afferents are also known to support social cognitive functions. Considering that social abilities are typically disrupted in ASD, evidence that common brain areas support both social cognition and CT-optimal touch highlights the presence of a potential link between this system and ASD (Kaiser et al. 2010). In line with this idea, McGlone et al. (2014) propose that a failure of the CT system to develop could have a significant impact on brain development, facilitating, for instance, the expression of ASD (McGlone et al. 2014). This association is also supported by findings showing that responses to touch in early social interactions may provide an important cue for identifying children at greater risk for social impairments related to autism spectrum behaviours (Mammen et al. $2015,2016)$. In line with this hypothesis, in a recent study, Kaiser et al. (2015) reported that children and adolescents with ASD show a reduced activation in response to gentle CT-touch over brain areas involved in social information processing, suggesting again a potential dysfunction in neurobehavioural social development and its link with critical periods of tactile experiences early in life. Nevertheless, the direct causal link between CT-system, body representation, social brain function, and the emergence of autistic traits is still unclear. While it is tempting to hypothesise the presence of a dysfunction of the CT-system at the emergence of this condition (Cascio 2010; McGlone et al. 2014), with repercussions in the subsequent emotional, affective, and social development, at present no studies have shown a CT-optimal touch failure specificity in ASD.

Autism is not the only disorder characterised by dysfunctional sensory responsiveness to CT-optimal touch. Recent findings suggest that patients with Anorexia Nervosa show a reduced perception of interpersonal affective touch (in terms of subjective pleasantness) compared to healthy controls (Crucianelli et al. 2016).

Anorexia Nervosa (AN) is an eating disorder of unknown aetiology, characterised by restricting eating, a pursuit of thinness, irrespective of actual body mass index, and obsessive fears of becoming fat (American Psychiatric Association 2013; Wagner et al. 2007). Disturbances in body representation and awareness are also a core feature in $\mathrm{AN}$. Given these clinical traits, recent years have seen an increasing attention in the study of body representation in AN by means of multisensory paradigms. For example, Eshkevari et al. (2012) found that AN patients are more susceptible to bodily illusions compared to healthy controls, suggesting that there may be an increased sensitivity for visual aspects of body perception in AN patients. These findings seem to suggest that bodily representation is highly malleable in AN or to use Legrand (2010) words, it is "dis-integrated", in the sense that eating disorders are not only characterized by over-objectification of their physical body but also by weakened body-ownership (Legrand 2010). Interestingly however, no studies in AN have accounted for the role of interoception in the construction of the bodily self. As discussed above, modalities such as affective touch challenge any rigid distinction between 'internal' and 'external' sensations. A recent study investigated the idea that $\mathrm{AN}$ patients may present reduced bodily pleasure, by examining the perception of pleasant touch in AN and healthy controls. Results showed that AN participants rated the pleasantness of the perceived touch as lower in both slow and fast velocities compared to healthy controls. This suggests a generally reduced bodily pleasure in AN subjects and a potentially dysfunctional CT afferents system, or an abnormal cognitive regulation of this system (Crucianelli et al. 2016). Nevertheless, pleasant ratings were influenced by social manipulations in similar fashion in AN patients and controls. Thus, these results indicate that perception of affective touch, rather than its 
social modulation may be affected in AN. This finding is in line with both the more general anhedonia observed in this population (i.e. inability to seek and enjoy pleasurable experiences) (Friederich et al. 2006; Kaye 2008; Soussignan et al. 2011; Tchanturia et al. 2012; Wagner et al. 2007) and the interoceptive impairment which also pervades other modalities, such as hunger and physical pain (e.g., Strigo et al. 2013), and a reduced capacity to accurately perceive one's heartbeat (Pollatos et al. 2008).

The evidence of a disordered perception of interpersonal affective touch in AN provides an important contribution because this clinical population is characterised by body image distortions which persist even after recovery, and might represent a risk factor for future relapses. Hence, we can hypothesise a link between the perception of affective touch, social anhedonia and distortion of body representation. In addition, patients with AN show a remarkable improvement in symptomatology after combining their standard therapy with massage therapy (Hart et al. 2001). Massage therapy seems to lower stress, depressed mood and anxiety level, as well as body dissatisfaction and eating disorders symptomatology, suggesting that this approach combined to standard care may be effective in specifically addressing body image issues in eating disorders (Hart et al. 2001; Field et al. 1996).

\section{Conclusions and Future Directions}

Over the last decade, investigation on the sense of touch has received increased interest by the scientific research community (Gillmeister et al. 2017). Specifically, empirical research on interpersonal affective touch has highlighted the importance of this modality for socio-emotional and physical development. Similarly, theoretical and philosophical approaches have focused on the key role played by touch for the development of the self (Ciaunica and Fotopoulou 2017). In this article, we have reviewed a significant body of work suggesting the need to conceptualise interpersonal affective touch as a fundamental selfregulatory and social component of the developing body. Firstly, we have described the developmental trajectories that interpersonal affective touch follows from the prenatal to the first developmental stages, which we believe represent the evolutionary scaffolding of body representation from within and from outside. The analysis of the earliest stages of tactile processing suggests that humans might have evolved to optimally respond to interpersonal affective touch. Indeed, this type of touch is also the one that we naturally use when asked to actively touch our partner or child (Croy et al. 2016), further supporting the idea that early tactile experiences might represent the scaffolding to self and other development. Tactile interactions that involve affective touch are thus fundamental in critical periods of development, when the infant is learning to respond to changes in their physiological balance as well as in the external environment. Through appropriate and prompt tactile exchanges the infant might learn to successfully regulate their internal and external bodily signals. From within, slow, gentle touch can provide feedback to physiological arousal states, shaping emotion-regulatory abilities. From outside, through the caregiver's prompt and appropriate response to the infant's cues, the infant learns to differentiate their body and thereby to establish successful social interactions.

Secondly, we have discussed the developmental consequences associated with touch deprivation in the first months of life and made the claim that severe reduction in interpersonal affective touch in these critical periods of development could have repercussions on the subsequent scaffolding of the sense of bodily-self and self-regulation, and thereby socio-emotional understanding. The research reviewed in this article is extremely important and timely. This work can help us to promote mental health from an early stage of life and to implement some protective actions that could reduce the negative consequences associated with unavailable or unbalanced interpersonal affective touch. For example, a study showed that depressed mothers who are encouraged to stroke their newborns during the first weeks of life, presented a reduced association between maternal depression and negative outcome later on in infancy (Sharp et al. 2012).

We also argued that sensory hypo-responsiveness to affective touch in developmental disorders such as ASD and in disorders of eating behaviour such as AN, could be accounted for a CT afferent pathology (Cascio 2010; Crucianelli et al. 2016), reinforcing the idea that critical brain regions support both the developing social brain and the functional development of the CT-system. Unfortunately, to our knowledge, no developmental studies have specifically focused on the role of interpersonal affective touch in the development of self-other differentiation, and its atypical trajectories. While the aforementioned research studies might tentatively suggest that a disrupted CT system may specifically account for atypical development of interoceptive and exteroceptive body representation and social cognitive abilities, future studies should experimentally address the interacting and interdependent neurobiological processes underpinning interpersonal affective touch, body representation, and social cognition from a developmental perspective.

In conclusion, through early proximal and embodied interactions with other bodies, affective touch may function as an experiential "glue" connecting the feeling of one's body from outside with the feeling of one's body from the inside. Infants' innate sensitivity to respond to affective touch, together with caregivers' ability to promptly and 
appropriately respond to the infants' cues are at the core of this gradual process of minimal self-awareness.

Funding This study was partially funded by the Fund for Psychoanalytic Research 2016/2017 through the American Psychoanalytic Association to LC.

\section{Compliance with Ethical Standards}

Conflict of interest The authors declare that they have no conflict of interest.

Ethical Approval This article does not contain any studies with human participants performed by any of the authors.

Open Access This article is distributed under the terms of the Creative Commons Attribution 4.0 International License (http://creativeco mmons.org/licenses/by/4.0/), which permits unrestricted use, distribution, and reproduction in any medium, provided you give appropriate credit to the original author(s) and the source, provide a link to the Creative Commons license, and indicate if changes were made.

\section{References}

Ackerley R, Wasling HB, Liljencrantz J, Olausson H, Johnson RD, Wessberg J (2014) Human C-tactile afferents are tuned to the temperature of a skin-stroking caress. J Neurosci 34(8):2879-2883

Ainsworth MS (1979) Infant-mother attachment. Am Psychol 34(10): 932

Ainsworth MDS, Bell SM (1974) Mother-infant interaction and the development of competence. In Connolly K, Bruner J (eds) The growth of competence. Academic Press, New York

American Psychiatric Association (2013) Diagnostic and Statistical Manual of Mental Disorders, 5th edn. American Psychiatric Association, Washington, DC

Arabin B, Bos R, Rijlaarsdam R, Mohnhaupt A, Van Eyck J (1996) The onset of inter-human contacts: longitudinal ultrasound observations in early twin pregnancies. Ultrasound Obstet Gynecol 8(3):166-173

Atkinson J, Braddick O (1982) Sensory and perceptual capacities of the neonate. In Stratton P (ed) Psychobiology of the human newborn. Wiley, London, pp 191-220

Atzil S, Barrett LF (2017) Social regulation of allostasis: commentary on "Mentalizing homeostasis: the social origins of interoceptive inference" by Fotopoulou and Tsakiris. Neuropsychoanalysis 19(1):29-33

Baibazarova E, van de Beek C, Cohen-Kettenis PT, Buitelaar J, Shelton KH, van Goozen SH (2013) Influence of prenatal maternal stress, maternal plasma cortisol and cortisol in the amniotic fluid on birth outcomes and child temperament at 3 months. Psychoneuroendocrinology 38(6):907-915

Bartocci M, Bergqvist LL, Lagercrantz H, Anand KJS (2006) Pain activates cortical areas in the preterm newborn brain. Pain 122(1):109-117

Beckett C, Maughan B, Rutter M, Castle J, Colvert E, Groothues C, Kreppner J, Stevens S, O'Connor TG, Sonuga-Barke EJ (2006) Do the effects of early severe deprivation on cognition persist into early adolescence? Findings from the English and Romanian adoptees study. Child Dev 77(3):696-711
Beebe B, Lachmann FM (1998) Co-constructing inner and relational processes: self-and mutual regulation in infant research and adult treatment. Psychoanal Psychol 15(4):480

Beebe B, Jaffe J, Markese S, Buck K, Chen H, Cohen P, Bahrick L, Andrews H, Feldstein S (2010) The origins of 12-month attachment: a microanalysis of 4-month mother-infant interaction. Attach Hum Dev 12(1-2):3-141

Bellieni CV, Cordelli DM, Marchi S, Ceccarelli S, Perrone S, Maffei M, Buonocore G (2007) Sensorial saturation for neonatal analgesia. Clin J Pain 23(3):219-221

Bennett RH, Bolling DZ, Anderson LC, Pelphrey KA, Kaiser MD (2013) fNIRS detects temporal lobe response to affective touch. Social Cognit Affect Neurosci 9(4):470-476

Bernhardt J (1987) Sensory capabilities of the fetus. MCN 12(1):44-47

Björnsdotter M, Löken L, Olausson H, Vallbo Å, Wessberg J (2009) Somatotopic organization of gentle touch processing in the posterior insular cortex. J Neurosci 29(29):9314-9320

Björnsdotter M, Morrison I, Olausson H (2010) Feeling good: on the role of $\mathrm{C}$ fiber mediated touch in interoception. Exp Brain Res 207(3-4):149-155

Blanke O (2012) Multisensory brain mechanisms of bodily self-consciousness. Nat Rev Neurosci 13(8):556

Blanke O, Metzinger T (2009) Full-body illusions and minimal phenomenal selfhood. Trends Cogn Sci 13(1):7-13

Bolis D, Schilbach L (2017) Beyond one Bayesian brain: Modeling intra-and inter-personal processes during social interaction: Commentary on "Mentalizing homeostasis: The social origins of interoceptive inference". by Fotopoulou Tsakiris. Neuropsychoanalysis 19(1):35-38

Bowlby J (1969) Attachment and loss v. 3. Random House. Furman, W., \& Buhrmester, D. (2009). Methods and measures: The network of relationships inventory: Behavioral systems version. Int J Behav Dev 33:470-478

Bremner AJ, Lewkowicz DJ, Spence C (2012) The multisensory approach to development. Multisensory development. Oxford University Press, Oxford, pp 1-26

Bystrova K (2009) Novel mechanism of human fetal growth regulation: a potential role of lanugo, vernix caseosa and a second tactile system of unmyelinated low-threshold C-afferents. Med Hypotheses 72(2):143-146

Cascio CJ (2010) Somatosensory processing in neurodevelopmental disorders. J Neurodev Disord 2(2):62

Cascio CJ, Moana-Filho EJ, Guest S, Nebel MB, Weisner J, Baranek GT, Essick GK (2012) Perceptual and neural response to affective tactile texture stimulation in adults with autism spectrum disorders. Autism Res 5(4):231-244

Cascio CJ, Gu C, Schauder KB, Key AP, Yoder P (2015) Somatosensory event-related potentials and association with tactile behavioral responsiveness patterns in children with ASD. Brain Topogr 28(6):895-903

Castiello U, Becchio C, Zoia S, Nelini C, Sartori L, Blason L, D'Ottavio G, Bulgheroni M, Gallese V (2010) Wired to be social: the ontogeny of human interaction. PLoS ONE, 5(10):e13199

Chugani HT, Behen ME, Muzik O, Juhász C, Nagy F, Chugani DC (2001) Local brain functional activity following early deprivation: a study of postinstitutionalized Romanian orphans. Neuroimage 14(6):1290-1301

Ciaunica A, Fotopoulou A (2017) The touched self: psychological and philosophical perspectives on proximal intersubjectivity and the self. In: Durt C, Fuchs T, Tewes C (eds) Embodiment, enaction, and culture-investigating the constitution of the shared world. MIT Press, Cambridge, MA, pp 173-192

Craig AD (2002) Opinion: How do you feel? Interoception: the sense of the physiological condition of the body. Nat Rev Neurosci 3(8):655 
Craig AD (2003) Interoception: the sense of the physiological condition of the body. Curr Opin Neurobiol 13(4):500-505

Craig AD (2008) Interoception and emotion: a neuroanatomical perspective. Handb Emot, 3(602):272-288

Craig AD (2009) How do you feel-now? The anterior insula and human awareness. Nat Rev Neurosci, 10(1):59-70

Craig AD (2010) The sentient self. Brain Struct Funct 214:563-577

Critchley HD, Wiens S, Rotshtein P, Dolan RJ (2004) Neural systems supporting interoceptive awareness. Nat Neurosci 7(2):189

Croy I, Luong A, Triscoli, C, Hofmann E, Olausson H, Sailer U (2016) Interpersonal stroking touch is targeted to $\mathrm{C}$ tactile afferent activation. Behav Brain Res SreeTestContent1 297:37-40

Crucianelli L, Metcalf NK, Fotopoulou AK, Jenkinson PM (2013) Bodily pleasure matters: velocity of touch modulates body ownership during the rubber hand illusion. Front Psychol, 4:703

Crucianelli L, Cardi V, Treasure J, Jenkinson PM, Fotopoulou A (2016) The perception of affective touch in anorexia nervosa. Psychiatry Res 239:72-78

Crucianelli L, Krahé C, Jenkinson PM, Fotopoulou AK (2017) Interoceptive ingredients of body ownership: affective touch and cardiac awareness in the rubber hand illusion. Cortex. https:// doi.org/10.1016/j.cortex.2017.04.018

Crucianelli L, Wheatley L, Filippetti ML, Jenkinson PM, Kirk E, Fotopoulou AK (2018) The mindedness of maternal touch: an investigation of maternal mind-mindedness and motherinfant touch interactions. Dev Cognit Neurosci. https://doi. org/10.1016/j.den.2018.01.010

Crusco AH, Wetzel CG (1984) The Midas touch: the effects of interpersonal touch on restaurant tipping. Pers Soc Psychol Bull 10(4):512-517

De Schipper JC, Tavecchio LWC, Van IJzendoorn MH, Van Zeijl J (2004) Goodness-of-fit in center day care: relations of temperament, stability, and quality care with the child's adjustment. Early Child Res Q 19(2):257-272

Dijkerman HC (2015) How do different aspects of self-consciousness interact? Trends Cognit Sci 19(8):427-428

Ebisch SJ, Ferri F, Gallese V (2014) Touching moments: desire modulates the neural anticipation of active romantic caress. Front Behav Neurosci 8:60

Eshkevari E, Rieger E, Longo MR, Haggard P, Treasure J (2012) Increased plasticity of the bodily self in eating disorders. Psychol Med 42(4):819-828

Fairhurst MT, Löken L, Grossmann T (2014) Physiological and behavioral responses reveal 9-month-old infants' sensitivity to pleasant touch. Psychol Sci 25(5):1124-1131

Feldman R, Weller A, Leckman JF, Kuint J, Eidelman AI (1999) The nature of the mother's tie to her infant: maternal bonding under conditions of proximity, separation, and potential loss. J Child Psychol Psychiatry Allied Dis 40(6):929-939

Feldman R, Eidelman AI, Sirota L, Weller A (2002) Comparison of skin-to-skin (kangaroo) and traditional care: parenting outcomes and preterm infant development. Pediatrics 110(1):16-26

Feldman R, Rosenthal Z, Eidelman AI (2014) Maternal-preterm skin-to-skin contact enhances child physiologic organization and cognitive control across the first 10 years of life. Biol Psychiatry 75(1):56-64

Ferber SG, Feldman R, Makhoul IR (2008) The development of maternal touch across the first year of life. Early Hum Dev 84(6):363-370

Field T (2002) Infants' need for touch. Hum Dev 45(2):100-103

Field T (2010) Touch for socioemotional and physical well-being: a review. Dev Rev 30(4):367-383
Field T, Grizzle N, Scafidi F, Abrams S, Richardson S, Kuhn C et al (1996) Massage therapy for infants of depressed mothers. Infant Behav Dev 19:107-112

Fonagy P, Campbell C (2017) What touch can communicate: commentary on "Mentalizing homeostasis: the social origins of interoceptive inference" by Fotopoulou and Tsakiris. Neuropsychoanalysis 19(1):39-42

Fotopoulou A, Tsakiris M (2017) Mentalizing homeostasis: the social origins of interoceptive inference. Neuropsychoanalysis 19(1):3-28

Friederich HC, Kumari V, Uher R, Riga M, Schmidt U, Campbell IC, Herzog W, Treasure J (2006) Differential motivational responses to food and pleasurable cues in anorexia and bulimia nervosa: a startle reflex paradigm. Psychol Med 36(9):1327-1335

Gallace A (2012) Living with touch. Psychologist 25(12):896-899

Gallace A, Spence C (2014) In touch with the future: the sense of touch from cognitive neuroscience to virtual reality. OUP, Oxford

Gazzola V, Spezio ML, Etzel JA, Castelli F, Adolphs R, Keysers C (2012) Primary somatosensory cortex discriminates affective significance in social touch. Proc Natl Acad Sci 109(25):E1657-E1666

Gergely G, Watson JS (1999) Early socio-emotional development: contingency perception and the social-biofeedback model. Early Social Cognit 60:101-136

Gergely G, Fonagy P, Jurist E, Target M (2002) Affect regulation, mentalization, and the development of the self. Other Press, New York

Gillmeister H, Bowling N, Rigato S, Banissy MJ (2017) Inter-individual differences in vicarious tactile perception: a view across the lifespan in typical and atypical populations. Multisens Res 30(6):485-508

Gong Y-H, Ji C-Y, Shan J-P (2013) Longitudinal study on infants' temperament and physical development in Beijing, China. Int J Nurs Pract 19(5):487-497

Hart S, Field T, Hernandez-Reif M, Nearing G, Shaw S, Schanberg S, Kuhn C (2001) Anorexia nervosa symptoms are reduced by massage therapy. Eat Disord 9(4):289-299

Herrera E, Reissland N, Shepherd J (2004) Maternal touch and maternal child-directed speech: effects of depressed mood in the postnatal period. J Affect Disord 81(1):29-39

Hertenstein MJ (2002) Touch: its communicative functions in infancy. Hum Dev 45(2):70-94

Hertenstein MJ, Campos JJ (2001) Emotion regulation via maternal touch. Infancy 2(4):549-566

Hertenstein MJ, Keltner D, App B, Bulleit BA, Jaskolka AR (2006) Touch communicates distinct emotions. Emotion 6:528-533

Hooker D (1943) Reflex activities in the human fetus. McGraw-Hill, New York

Hooker D (1952) Early human fetal activity. Anat Rec 113(4):503

Humphrey T (1966) The development of the human hippocampal formation correlated with some aspects of its phylogenetic history. In: Evolution of the forebrain. Springer, Boston, MA, pp 104-116

Jahromi LB, Putnam SP, Stifter CA (2004) Maternal regulation of infant reactivity from 2 to 6 months. Dev Psychol 40(4):477

Jean AD, Stack DM, Arnold S (2014) Investigating maternal touch and infants' self-regulatory behaviours during a modified faceto-face Still-Face with Touch procedure. Infant Child Dev 23(6):557-574

Kaiser MD, Hudac CM, Shultz S, Lee SM, Cheung C, Berken AM, Deen B, Pitskel NB, Sugrue DR, Voos AC, Saulnier CA (2010) Neural signatures of autism. Proc Natl Acad Sci 107(49):21223-21228

Kaiser MD, Yang DYJ, Voos AC, Bennett RH, Gordon I, Pretzsch C, Beam D, Keifer C, Eilbott J, McGlone F, Pelphrey KA (2015) 
Brain mechanisms for processing affective (and nonaffective) touch are atypical in autism. Cereb Cortex 26(6):2705-2714

Karnath HO, Baier B (2010) Right insula for our sense of limb ownership and self-awareness of actions. Brain Struct Funct 214(5-6):411-417

Karnath HO, Baier B, Nägele T (2005) Awareness of the functioning of one's own limbs mediated by the insular cortex? J Neurosci 25(31):7134-7138

Kaye W (2008) Neurobiology of anorexia and bulimia nervosa. Physiol Behav 94(1):121-135

Kirsch LP, Krahé C, Blom N, Crucianelli L, Moro V, Jenkinson PM, Fotopoulou A (2017) Reading the mind in the touch: neurophysiological specificity in the communication of emotions by touch. Neuropsychologia. https://doi.org/10.1016/j.neuropsychologi a.2017.05.024

Kopp CB (1989) Regulation of distress and negative emotions: a developmental view. Dev Psychol 25(3):343

Lagercrantz H, Slotkin TA (1986) The" stress" of being born. Sci Am 254(4):100-107

Legrand D (2010) Subjective and physical dimensions of bodily selfconsciousness, and their dis-integration in anorexia nervosa. Neuropsychologia 48(3):726-737

Levav J, Argo JJ (2010) Physical contact and financial risk taking. Psychol Sci 21(6):804-810

Lloyd DM, Gillis V, Lewis E, Farrell MJ (2013) Pleasant touch moderates the subjective but not objective aspects of body perception. Front Behav Neurosci 7:207

Löken LS, Olausson H (2010) The skin as a social organ. Exp Brain Res 204(3):305-314

Löken LS, Wessberg J, McGlone F, Olausson H (2009) Coding of pleasant touch by unmyelinated afferents in humans. Nat Neurosci 12(5):547-548

Lowe JR, Coulombe P, Moss NC, Rieger RE, Aragón C, MacLean PC, Caprihan A, Phillips JP, Handal AJ (2016) Maternal touch and infant affect in the still face paradigm: a cross-cultural examination. Infant Beh Dev 44:110-120

MacLean K (2003) The impact of institutionalization on child development. Dev Psychopathol 15:853-884

Maitre NL, Key AP, Chorna OD, Slaughter JC, Matusz PJ, Wallace MT, Murray MM (2017) The dual nature of early-life experience on somatosensory processing in the human infant brain. Curr Biol 27(7):1048-1054

Malphurs JE, Raag T, Field T, Pickens J, Peláez-Nogueras M (1996) Touch by intrusive and withdrawn mothers with depressive symptoms. Early Dev Parent 5(2):111-115

Mammen MA, Moore GA, Scaramella LV, Reiss D, Ganiban JM, Shaw DS, Leve LD, Neiderhiser JM (2015) Infant avoidance during a tactile task predicts autism spectrum behaviors in toddlerhood. Infant Mental Health J 36(6):575-587

Mammen MA., Moore GA, Scaramella LV, Reiss D, Shaw DS, Leve LD, Neiderhiser JM (2016) Infant patterns of reactivity to tactile stimulation during parent-child interaction. Infant Behav Dev 44:121-132

Marx V, Nagy E (2015) Fetal behavioural responses to maternal voice and touch. PLoS ONE, 10(6):e0129118

McGlone F, Kelly EF, Trulsson M, Francis ST, Westling G, Bowtell R (2002) Functional neuroimaging studies of human somatosensory cortex. Behav Brain Res 135(1):147-158

McGlone F, Wessberg J, Olausson H (2014) Discriminative and affective touch: sensing and feeling. Neuron 82(4):737-755

Meins E, Fernyhough C, Fradley E, Tuckey M (2001) Rethinking maternal sensitivity: mothers' comments on infants' mental processes predict security of attachment at 12 months. J Child Psychol Psychiatry Allied Discipl 42(5):637-648
Merleau-Ponty M (1964) The primacy of perception and its philosophical consequences. Northwestern University Press, Evanston

Montague A (1978) Touching. Perennial Library, New York

Moore ER, Bergman N, Anderson GC, Medley N (2016) Early skin-toskin contact for mothers and their healthy newborn infants. The Cochrane Library, London

Morrison I, Löken L, Olausson H (2010) The skin as a social organ. Exp Brain Res 204:305-314

Moszkowski RJ, Stack DM, Girouard N, Field TM, Hernandez-Reif M, Diego M (2009) Touching behaviors of infants of depressed mothers during normal and perturbed interactions. Infant Behav Dev 32(2):183-194

Murray L, Cooper PJ (1997) Postpartum depression and child development. Psychol Med 27(2):253-260

Nelson CA, Zeanah CH, Fox NA, Marshall PJ, Smyke AT, Guthrie D (2007) Cognitive recovery in socially deprived young children: the Bucharest Early Intervention Project. Science 318(5858): 1937-1940

Olausson H, Lamarre Y, Backlund H, Morin C, Wallin BG, Starck G, Ekholm S, Strigo I, Worsley K, Vallbo ÅB, Bushnell MC (2002) Unmyelinated tactile afferents signal touch and project to insular cortex. Nat Neurosci 5(9):900

Peláez-Nogueras M, Field T, Gewirtz JL, Cigales M, Gonzalez A, Sanchez A, Richardson SC (1997) The effects of systematic stroking versus tickling and poking on infant behavior. J Appl Dev Psychol 18(2):169-178

Penfield W, Boldrey E (1937) Somatic motor and sensory representation in the cerebral cortex of man as studied by electrical stimulation. Brain 60:389-443

Pollatos O, Kurz AL, Albrecht J, Schreder T, Kleemann AM, Schöpf V, Kopietz R, Wiesmann M, Schandry R (2008) Reduced perception of bodily signals in anorexia nervosa. Eating behav 9(4):381-388

Reece C, Ebstein R, Cheng X, Ng T, Schirmer A (2016) Maternal touch predicts social orienting in young children. Cognit Dev 39:128-140

Rigato S, Ali JB, van Velzen J, Bremner AJ (2014) The neural basis of somatosensory remapping develops in human infancy. Curr Biol 24(11):1222-1226

Rothbart MK, Ziaie H, O'boyle CG (1992) Self-regulation and emotion in infancy. New Dir Child Adolesc Dev 1992(55):7-23

Saby JN, Meltzoff AN, Marshall PJ (2015) Neural body maps in human infants: Somatotopic responses to tactile stimulation in 7-montholds. NeuroImage 118:74-78

Serino A, Haggard P (2010) Touch and the body. Neurosci Biobehav Rev 34(2):224-236

Sharp GC, Stock SJ, Norman JE (2012) Fetal assessment methods for improving neonatal and maternal outcomes in preterm prelabour rupture of membranes. Database Syst Rev. https://doi. org/10.1002/14651858.CD010209.pub2

Shibata M, Fuchino Y, Naoi N, Kohno S, Kawai M, Okanoya K, Myowa-Yamakoshi M (2012) Broad cortical activation in response to tactile stimulation in newborns. Neuroreport 23(6):373-377

Soussignan R, Schaal B, Rigaud D, Royet JP, Jiang T (2011) Hedonic reactivity to visual and olfactory cues: rapid facial electromyographic reactions are altered in anorexia nervosa. Biol Psychol 86(3):265-272

Stack DM, Muir DW (1992) Adult tactile stimulation during face-toface interactions modulates five-month-olds' affect and attention. Child Dev 63(6):1509-1525

Stack DM, LePage DE, Hains S, Muir DW (1996) Qualitatitive changes in maternal touch as a function of instructional condition during face-to-face social interactions. Infant Behav Dev 19:761 
Sterman AB, Schaumburg HH, Asbury AK (1980) The acute sensory neuronopathy syndrome: a distinct clinical entity. Ann Neurol 7(4):354-358

Strigo IA, Matthews SC, Simmons AN, Oberndorfer T, Klabunde M, Reinhardt LE, Kaye WH (2013) Altered insula activation during pain anticipation in individuals recovered from anorexia nervosa: evidence of interoceptive dysregulation. Int J Eat Disord 46(1):23-33

Tchanturia K, Davies H, Roberts M, Harrison A, Nakazato M, Schmidt U, Tressure J, Morris R (2012) Poor cognitive flexibility in eating disorders: examining the evidence using the Wisconsin Card Sorting Task. PLoS ONE, 7(1):e28331

Tronick EZ, Gianino AF (1986) The transmission of maternal disturbance to the infant. New Dir Child Adolesc Dev 1986(34):5-11

Trulsson M, Francis ST, Kelly EF, Westling G, Bowtell R, McGlone F (2001) Cortical responses to single mechanoreceptive afferent microstimulation revealed with fMRI. Neuroimage 13(4):613-622

Tuulari JJ, Scheinin NM, Lehtola S, Merisaari H, Saunavaara J, Parkkola R, Sehlstedt I, Karlsson L, Karlsson H, Björnsdotter M (2017) Neural correlates of gentle skin stroking in early infancy. Dev Cognit Neurosci. https://doi.org/10.1016/j.den.2017.10.004

Underdown A, Barlow J, Chung V, Stewart-Brown S (2006) Massage intervention for promoting mental and physical health in infants aged under six months. Cochrane Database Syst Rev. https://doi. org/10.1002/14651858.CD005038.pub2

Vallbo ÅB, Olausson H, Wessberg J (1999) Unmyelinated afferents constitute a second system coding tactile stimuli of the human hairy skin. J Neurophysiol 81(6):2753-2763

Van Stralen HE, Van Zandvoort MJE, Dijkerman HC (2011) The role of self-touch in somatosensory and body representation disorders after stroke. Philosophical Transactions of the Royal Society of London B: Biological Sciences 366(1581):3142-3152

van Stralen HE, van Zandvoort MJ, Hoppenbrouwers SS, Vissers LM, Kappelle LJ, Dijkerman HC (2014) Affective touch modulates the rubber hand illusion. Cognition 131(1):147-158

Veenstra R, Lindenberg S, Oldehinkel AJ, de Winter AF, Ormel J (2006) Temperament, environment, and antisocial behavior in a population sample of preadolescent boys and girls. Int J Behav Dev 30(5):422-432

von Mohr M, Kirsch LP, Fotopoulou A (2017) The soothing function of touch: affective touch reduces feelings of social exclusion. Sci Rep 7:13516

Voos AC, Pelphrey KA, Kaiser MD (2012) Autistic traits are associated with diminished neural response to affective touch. Social Cognit Affect Neurosci 8(4):378-386

Wagner A, Aizenstein H, Venkatraman VK, Fudge J, May JC, Mazurkewicz L, Frank GK, Bailer UF, Fischer L, Nguyen V, Carter C (2007) Altered reward processing in women recovered from anorexia nervosa. Am J Psychiatry 164(12):1842-1849

Walker SC, McGlone FP (2013) The social brain: neurobiological basis of affiliative behaviours and psychological well-being. Neuropeptides 47(6):379-393

Wang ZW, Hua J, Xu YH (2015) The relationship between gentle tactile stimulation on the fetus and its temperament 3 months after birth. Behav Neurol. https://doi.org/10.1155/2015/371906

Weiss SJ, Wilson P, Hertenstein MJ, Campos R (2000) The tactile context of a mother's caregiving: implications for attachment of low birth weight infants. Infant Behav Dev 23(1):91-111 